\title{
Toward Renewed Constructions of Masculinity and Femininity: Measuring Significant Psychological Differences between Young Men and Women's Subjective Experiences in Their Romantic Relationships
}

\author{
Nicolas Gabbay (Corresponding author) \\ School of Psychology, University of Ottawa \\ 136 Jean-Jacques Lussier, Ottawa, Ontario, K1N6N5, Canada \\ Tel: 1-613-562-5800 x 4471 E-mail: ngabb095@uottawa.ca \\ Marie-France Lafontaine \\ School of Psychology, University of Ottawa \\ 136 Jean-Jacques Lussier, Ottawa, Ontario, K1N6N5, Canada \\ Tel: 1-613-562-5800 x 2498 E-mail: mlafonta@uottawa.ca \\ Claude Lamontagne \\ School of Psychology, University of Ottawa \\ 136 Jean-Jacques Lussier, Ottawa, Ontario, K1N6N5, Canada \\ Tel: 1-613-562-5800 x 4300 E-mail: clamonta@uottawa.ca
}

Received: September 8, $2011 \quad$ Accepted: September 27, $2011 \quad$ Published: December 1, 2011

doi:10.5539/ijps.v3n2p200

URL: http://dx.doi.org/10.5539/ijps.v3n2p200

\begin{abstract}
The present study focuses on newly conceptualized and observed significant differences between men and women regarding their subjective experience of their intimate relationships. The experimental paradigm was based on a new theory of masculinity and femininity developed by Lamontagne (2010), proposing one respective factor per dimension. This study (1) re-evaluates Lamontagne's initial findings using a modified qualitative tool and a new quantitative measure: The Questionnaire of Objectality and Subjectality (QOS; Gabbay, 2010); (2) verifies the QOS' psychometric properties; (3) evaluates inter-sex differences on proposed factors; and (4) examines complementarity of femininity and masculinity between romantic partners. The modified qualitative tool, the Bem Sex Role Inventory (BSRI; Bem, 1974), and the QOS were administered to 134 individuals. Findings supported a theoretically coherent factor structure. Subscales demonstrated good reliability and the expected correlations with the BSRI. Gender differences were qualitatively and quantitatively significant. Within couples, partners' relative femininity and masculinity were complementary.
\end{abstract}

Keywords: Masculinity, Femininity, Qualitative and quantitative psychometrics, Heterosexual couples

\section{Introduction}

The duality between masculinity and femininity has always fascinated philosophers and researchers alike. Interest in this topic dates back to very primitive periods, as illustrated by the existence of the yin/yang model (Porkert, 1973), and has also persisted in more modern times, as demonstrated by the development of the Jungian animus/anima theory and various psychometric inventories (Bouchard \& Gingras, 2007). Researchers also generally seem to have an interest in the overall field of gender differences, irrespective of the specific variables being studied. However, despite this demonstrated interest and the firm establishment of empirical science in the field of contemporary psychology, it seems - with all due respect of course - that sex role theories (and the psychometric inventories that are derived from them) still remain, to this day, somewhat sexist and even heterosexist. When saying that an individual doesn't meet the criteria of an inventory to be "masculine", the underlying message is that he is not a man. If a man is emotional instead of macho or skinny rather than muscular, is he less of a man than others? Contemporary liberal ways of thinking would say no, but this is a fact 
that has yet to be reflected, to our knowledge, in empirical psychology and in psychometric testing (as reflected by the item content of diverse inventories presented below).

The main focus of this study is to humbly propose new directions for sex role theories by presenting a new theory of femininity and masculinity (initially elaborated by Lamontagne in 2009). Following empirical recommendations made by the theory's author, significant differences between men and women in their respective experiences in romantic relationships were used to reflect core psychological specificities respective to men and women. Although the scope of possible applications of these new directions is described below, masculinity and femininity were studied in the context of romantic relationships because: 1) These constructs often manifest themselves in partner selection (e.g., Smith, Byrne, \& Fielding, 1995) and 2) The factors proposed by the theory were observable in men and women's day-to-day relationship behaviours, and as such, were tested in an inductive fashion. Because our experimental paradigm was set around a new theoretical approach (Lamontagne, 2009), the article offers only a brief review of pertinent existing measures that claim to accurately represent masculinity and femininity. The review will provide insight into current perspectives (both empirical and popular) concerning the core constellation of traits that define sex roles, but will also serve as a base in order to examine some of the logical inconsistencies inherent to the existing applied approaches.

\subsection{Current Approaches}

The literature in this field of study reflects the popular view that masculinity and femininity constitute meta-constructs composed of multiple traits. Many, if not all of the articles that tackle the challenge of officially defining sex roles use taxonomic approaches (e.g., Bem, 1974; David \& Brannon, 1976; Levant \& Fischer, 1998) to identify the traits and behaviours considered to be feminine or masculine. Prior to a discussion of masculinity and femininity as popularly defined today, a review of empirical definitions of these concepts is essential.

First, the Bem Sex Role Inventory (BSRI; Bem, 1974) is a non-recent but psychometrically valid and frequently used (Oswald, 2004) inventory designed to measure androgyny. The inventory uses an entirely trait-based (not grouped by factors) approach to evaluating traits hypothesized to characterize femininity or masculinity. The BSRI is composed of 20 masculine traits (or items), including "aggressive, ambitious, dominant, athletic, independent, masculine, and self-sufficient;" 20 feminine traits, including "shy, faithful, feminine, friendly, affectionate, and tender;" and 20 neutral traits, including "sincere, amiable, and jealous." The neutral traits serve as distracters. The statistical distribution of frequencies obtained by heterosexual men and women is then used to confirm the validity of categorizing a trait as masculine or feminine.

Where contemporary masculinity ideology is concerned, the Male Role Norms Inventory - Revised (MRNI-R; Levant, Richmond, Cook, Tanner House, \& Aupont, 2007) clarifies the portrait of typical masculinity very adequately. The inventory is rooted in a theory (see David \& Brannon, 1976) that defines masculinity based on four factors: "no sissy stuff," representing men's typical avoidance of stereotypically feminine behaviour; "the big wheel," that is, the idea that masculine men should always be hard at work in order to achieve the greatest possible success; "the sturdy oak," that is, the idea that men should never show signs of weakness; and finally "give "em hell," representing men's supposed character in terms of sense of adventure, even in the presence of danger. The MRNI-R is the most recent revision (2007) of this scale, and includes 7 subscales: avoidance of femininity, fear and hatred of homosexuals, extreme self-reliance, aggression, dominance, non-relational attitudes toward sexuality, and restrictive emotionality.

Similar to the MRNI-R, the Feminine Ideology Scale (FIS; Levant, Richmond, Cook, Tanner House, \& Aupont, 2007 ) is an inventory that adequately represents contemporary femininity. The tool is composed of 5 subscales, and each subscale is designed to measure 1 factor: stereotypical image and activities, dependence/deference, purity, caretaking, and emotionality. Although the number of approaches to masculinity and femininity ideologies is quite large, Pleck (1995) and Shrock and Shwalbe (2009) acknowledged the existence of a constellation of norms rooted in Occidental society. The factors presented above seem to classify masculine and feminine factors into more or less accurate representations of current scientific and popular masculinity and femininity ideologies. Based on the traits presented above, one can also argue that, in terms of psychometric tools available today, these constitute quite conservative views of masculine and feminine ideology.

\subsection{A New Theory of Underlying Psychological Specificities}

The concepts of objectality and subjectality, respectively attributed to masculinity and femininity, are based on Brentano's (1874/1944) notion of intentionality. The notion specifies that all psychic events imply tension between the subject (the experiencing entity) and the object (the experienced entity). For example, a man who is holding a woman is understood to be the experiencing entity, whereas the woman being held is considered to be the experienced entity. Though both parties are "experiencing" the act, there are clear giving and receiving roles. 
In the context of the theory, experiencing entities project their energy onto objects, whereas experienced entities are the recipients of such energy. Masculinity is defined as primarily objectal, and is based on a self-world duality wherein the world is understood by the subject-self. Symmetrically, femininity is primarily subjectal, and is based on a self-world duality wherein the world is the subject that understands the self, which has, in turn, become the object. In other words, masculinity involves striving to understand whereas femininity involves striving to be understood. Masculinity implies a drive to reduce the tension of intentionality, by searching to integrate object-selves into the subject-self. In contrast, femininity implies a drive to reduce tension by searching to be integrated into another subject-self.

In the context of sensual and romantic relationships and of this study, masculine individuals are hypothesized to act as subjects (generally using active verb conjugations or expressions during qualitative data collection), whereas feminine individuals are hypothesized to act as objects (passive form of verb conjugation or use of expressions). Objectality can be defined as a person's tendency to seek an object to be a target of his or her energy, whereas subjectality can be defined as a person's tendency to seek a subject who will focus energy on him or her. In more informal and brief terms, masculinity or objectality is characterized by a desire to love and femininity is characterized by a desired to be loved (Note 1). It is important to emphasize that the terms "object" and "subject" are defined according to projection and reception of energy, and that the term "object" should not be interpreted as pejorative. The give and take of energy includes a variety of romantic behaviours such as caressing (objectal), leaning in to kiss (objectal), being kissed (subjectal), actively pursuing potential partners (objectal), and wanting to receive compliments (subjectal). An example of objectality in a non-romantic context would be men's attraction (i.e., more than women) to fields of study such as engineering or mechanics, in which their innate tension reduction mechanism manifests itself through object oriented tasks (i.e., dismantling an engine). Conversely, women - who generally strive to be understood - are often (i.e., more than men) attracted to the social sciences. As aforementioned, the theory was applied to romantic relationships to clearly illustrate fundamental differences between men and women on this level. Although objectality and subjectality were originally conceived to transcend various spheres of life, the present article solely focuses on relationships. As such, objectality and subjectality in relationships can be viewed as incremental contributions to new directions for masculine and feminine ideologies rather than integral replacements for the concepts of masculinity and femininity.

Although Lamontagne (2010) presents "femininity" and "masculinity" as fundamental opposites on the spectrum of psychological male/female duality, he conceptualizes masculinity and femininity on a single bipolar dimension. The continuum is characterized by a proportion of $0 \%$ femininity and $100 \%$ masculinity at one end $(0 \% \mathrm{~F} / 100 \% \mathrm{M})$ and $100 \%$ femininity and $0 \%$ masculinity $(100 \% \mathrm{~F} / 0 \% \mathrm{M})$ at the opposite end. In contrast, a double scale was used in the present study: it places each individual on a masculinity continuum ranging from $0 \% \mathrm{M}$ to $100 \% \mathrm{M}$ and a parallel femininity continuum ranging from $0 \% \mathrm{~F}$ to $100 \% \mathrm{~F}$, much like how Bem (1974) originally conceived her scales. This scale is based on the popular idea of feminine and masculine "sides" that are considered to be present in each of us. Rather than limiting an individual to a scale that sacrifices one "side" in favour of the other, the parallel continuums assign every individual a score on both scales (for example, $100 \%$ masculine and $20 \%$ feminine). This conceptualization of masculinity and femininity incorporates the concepts of androgyny and asexuality, that is, an individual can be $100 \%$ feminine and $100 \%$ masculine, or $0 \%$ feminine and $0 \%$ masculine.

\section{Epistemological Considerations}

\subsection{Is Categorizing Surface Traits in Order to Define Femininity and Masculinity Legitimate?}

According to Watzlawik (2009), current literature in the field of sex roles seems to reflect a preference for defining the psychological concepts of masculinity and femininity in a sociological manner, through the use of deductive processes (e.g., Levant, Hirsch, Celentano, Cozza, Hill, MacEachern, Marty, \& Schnedeker, 1992). This approach involves identifying attributes perceived to be socially acceptable for men and women, and analyzing the degree of correlation between respective attributes and genders. The process of classifying traits as either "masculine" or "feminine" is based on perceptions that given traits are more likely to be present in one sex than in the other (Watzlawik, 2009). The existing constructs of femininity and masculinity are obviously the function of researchers' personal beliefs (which often reflect beliefs shared by the general population). As illustrated in the factors presented above, researchers have individual - and generally archetypal conceptualizations of masculinity and femininity, and test their models for accuracy of fit in the general population. However, recent research (see Watzlawik, 2009) has demonstrated that many traits overlap in their distributions across genders; this finding poses a problem in terms of the legitimacy of assigning a surface trait exclusively to one sex over the other. 
In this context, the distinction between surface traits and fundamental traits is made because the theory proposes new fundamental dimensions. As a guideline here, surface traits are defined as ones that are not present in each and every individual. Conversely, a fundamental trait is seen here as one that transcends all people. To illustrate, traits such as "jealous", "aggressive" and "dominant" fall into the category of surface traits because although they may be present in many individuals, not everyone would identify with one or more of them. On the other hand, traits such as "anxious over abandonment", "avoidant" or "secure" are seen as fundamental in the sense that they are universal. All people are able to obtain a combined location on the orthogonal dimensions of attachment as theorized by Bowlby (1969/1982). Attachment type is a fundamental trait that exists in all people regardless of the variation of surface traits that contribute to define them. Below, we will advance the notion that the case is similar for objectality and subjectality.

The logic problems inherent in efforts to separate common characteristics by gender are considerable. Even in the event that a surface trait (such as physical appearance, aggression, or emotionality) is more often present in one sex than in the other, it cannot necessarily be qualified as an integral component of femininity or masculinity. To illustrate the danger of this common approach to classifying traits, consider, for example, the number of articles that have "empirically proven" that homophobia is an integral feature of masculinity (e.g., Levant et al., 1992; Pascoe, 2007; Schrock \& Schwalbe, 2009), due to its wide presence among heterosexual men (Note 2). A degree of common sense must be used when integrating such traits into concepts as fundamental as masculinity. When a group of heterosexual men is asked to supply their perspective about homosexuality, the majority of them must have reported supporting homophobia for this factor to be psychometrically included in the MRNI-R. However, using this finding as a rationale for integrating homophobia into the definition of masculinity is unreasonable. Consider the example of asking men to indicate their preference for wine or beer. In this example, it is foreseeable that men as a group would unanimously choose beer over wine. Similarly to homophobia, preference for beer is common among men, but has nothing to do with masculinity per se. In the same vein, where does this leave gay men vis-à-vis their masculinities? A further problem in many conceptualizations of masculinity and femininity is the following: often, the ubiquitous presence of a characteristic in one sex automatically excludes that trait from inclusion in the other sex's ideology. For example, traits such as "independent," "self-reliant," and "self-sufficient" are considered to be exclusive to masculinity in the BSRI, the MRNI-R, and, implicitly, in the FIS. Is it not alarming that these traits have been attributed exclusively to masculinity, as defined today, and consequently excluded from definitions of femininity?

Although certain traits seem to be more common in one sex, and popular culture endorses the social acceptance of certain traits for each gender, society may be focusing too much on surface traits at the expense of exploring deeper psychic traits (i.e., fundamental traits). When one considers one's personal conceptualizations of femininity and masculinity, distinctly stereotypical traits such as tender and delicate, and aggressive, strong, and sporty certainly come to mind. Is it possible to conduct research at a level of abstraction elevated enough to eliminate biases? Could higher-order traits distinguishing men from women exist? The distributions would have to be significantly distinct (despite overlap due to the existence of feminine men and masculine women), while maintaining a level of abstraction high enough to permit the identification of the features of ultimate masculinity and ultimate femininity. Rather than evoking multiple types of masculinities or femininities, fundamental factors would be applicable to all individuals, regardless of surface traits. In other words, according to the new proposed theory (Lamontagne, 2010), an emotional, dependent, non-athletic, and physically weak man could be considered to be $100 \%$ "masculine." Correspondingly, an aggressive, independent, and socially powerful woman could be considered to be $100 \%$ "feminine." The theory proposes concepts designed to describe masculinity and femininity at a more abstract and transcendent level, but also with the potential to predict and explain certain behaviours. Retaining traditional methods, the present study uses this theory to evaluate men's tendency to be "objectal" and women's tendency to be "subjectal." Though this method may be similar to current approaches, the proposed terms are applicable to both men and women, and do not create negative consequences for individuals who do not adhere to traditional roles. Rather than breaking down masculinity and femininity into surface traits, the terms of objectality and subjectality allow for symmetry of constructs, and address the essential nature of the concepts. However, the approach of classifying traits and correlating them with gender remains and will remain popular because it is essential at a theoretical level. Whether we like it or not, this method will always be present to some degree, because defining concepts such as masculinity and femininity requires acknowledgement of the fundamental differences between genders. The proposed factors highlight the critical differences between the two sexes, without threatening the images of individuals who do not adhere to the typical, socially accepted model. We believe that, regardless of surface traits, the psychological specificity that is objectality will be mainly dominant in most men, whereas subjectality will be dominant in most women. 


\subsection{The Common Variance}

Evolution in current thought about masculinity and femininity (as a function of our ever-evolving society) must also be taken into account; one example is the recent increase in acceptance of soft-spoken, emotional men. It is clear that (heterosexual) men and women who do not adhere to the stereotypical models of femininity and masculinity exist in the general population. Some researchers (see Smiler 2004 for a review) have tried to address this issue by evoking multiple types of masculinity and femininity; their models hypothesize that masculinity and femininity are subjective concepts that vary from person to person, and between cultures. However, this type of research is incompatible with the final objective of identifying common factors that would apply to each and every individual; that is, defining an ultimate (Note 3) femininity and masculinity. As defined by the theory presented here, the concepts of "femininity" and "masculinity," are complementary aspects of a psychic dynamic relevant to all individuals, male or female, heterosexual or homosexual. The theory does not focus on acquired characteristics and traits (i.e., physical appearance, emotional expressivity, etc.) because they are surface traits and will always be subject to cultural influence (i.e., social requirement that men inhibit their emotions). The notions of objectality and subjectality are designed to represent men's and women's psychological repercussions of basic biological and primal instincts; theoretically, these characteristics should be more universal than are surface traits. Objectality and subjectality should not be seen as the primary motivations driving people's pursuit of partners, but rather as explicative factors as to how (in an objectal or subjectal fashion) and why (objectality and subjectality being dictated by their innate biopsychology).

\section{Initial Empirical Testing and Post-hoc Measurement Modifications}

\subsection{Initial Results}

Lamontagne's initial hypothesis (2010) - suggesting that men were primarily objectal in contrast to women, who were primarily subjectal - was partially refuted during preliminary empirical testing. Lamontagne used a qualitative measure that required participants to write a paragraph describing an ideal sensual encounter with the ideal mate. The paragraphs were analyzed by judges who were familiar with the theoretical constructs (inter-rater reliability ranged from .90 to .98 ), in order to determine the number of "masculine" (objectal) and "feminine" (subjectal) expressions in each participant's paragraph. The results were used to place participants on the bipolar continuum initially presented by Lamontagne (2010), based on the ratio of masculine to feminine expressions used in the paragraph. According to the results obtained, the majority of men (79\%) were "primarily objectal." For women, a bimodal distribution was observed, refuting the idea that women were "primarily subjectal." This finding prompted Lamontagne to reformulate his initial hypothesis. The new hypothesis maintained that men are primarily objectal. However, rather than suggesting that women are primarily subjectal, the new hypothesis proposed that, as a group, women are less objectal than are men.

The absence of variability among men (in contrast to the observed within-group variability among women) may be explained by the fact that men (or masculine people) seem to interiorize social norms more than do their feminine counterparts. Conforming to cultural norms is an advantage for masculine individuals, in that it allows them to maintain power structures both at home and at work (Schrock \& Schwalbe, 2009). Moreover, it seems that men may adhere more rigorously to social norms than do women, for fear of the negative consequences of diverging from traditional roles (Schrock \& Schwalbe, 2009). That is, men (both heterosexual and homosexual) face greater social restrictions against stereotypically feminine behaviour (David \& Brannon, 1976; Levant et al., 2007; Taywaditep, 2001). In contrast, the rise of the feminist movement encouraged "masculine empowerment" in women (Connell, 1993; Lisak, 2000, as cited by Smiler, 2004) and removed many of the former restrictions on acceptable behaviour for women. The discrepancy between men and women in severity of negative consequences for "atypical" gender behaviour may have increased the variability observed in the female participants' empirical data. Further, the observed variability may have been the function of measurement error (French language usually favouring the active form of verb conjugation) or error of analysis (unequal number of expressions between paragraphs). All things considered, it would be interesting to retain and retest this initial hypothesis with the modified qualitative tools presented below.

\subsection{Modifications to the Qualitative Tool for the Present study}

In contrast to the more open writing task used by Lamontagne (2010), the qualitative tool administered in the present study was modified based on the reasoning presented above. The mandatory use and conjugation of 5 verbs allowed for more homogenous data collection, and facilitated inter-paragraph comparison by controlling the quantity and type of expressions used. In addition, the new list offered the explicit choice between the active and passive forms of each verb (i.e., to kiss/to be kissed). As mentioned above, in the context of this theory, the use of expressions illustrating subjects' desire to project their energy was considered to be "masculine" (objectal), 
whereas the use of expressions demonstrating a desire for receipt of energy was considered to be "feminine" (subjectal). During preliminary empirical data collection, only the active forms were provided, and the participants chose on their own whether or not to add an auxiliary verb to create the passive form. The exclusive provision of the active form during preliminary testing may explain the trend toward more masculine paragraphs in the preliminary trials. The presentation of both forms was designed to evaluate participants' personal preferences and to provide them with the option of using the passive form. Since the plural form ("we") cannot be scored (no projection or reception of energy), in order to maximize the number of viable paragraphs, participants were asked to refrain from using "we" (see Table 1 for a comparison of the initial and modified qualitative tool instructions).

\subsection{Creation of the Questionnaire}

The task described above was the only measure used in the initial testing of the theory. The task required the participant to write a paragraph describing an ideal sensual encounter. Because the obtained final score was a ratio (i.e., ratio of the number of masculine expressions to the number of feminine expressions), use of the double continuum presented above was not possible. To enable the use of the continuum, a quantitative measure was developed. The use of this tool allowed participants to obtain positive scores on both masculine and feminine items, and permitted evaluation of their choice of objectal or subjectal behaviour in the hypothetical scenario. Participants' final scores were therefore not limited to a ratio of used verbs, and included the possibility of high scores ("slightly agree" to "strongly agree") or low scores ("slightly disagree" to "strongly disagree") on both scales. These combinations also allowed for divergent scores (i.e., high score on one scale and low score on the other) and scores reflecting androgyny (high scores on both scales) and asexuality (low scores on both scales).

Although it is theoretically possible for an individual to score, for example, $100 \%$ on the feminine scale and $20 \%$ on the masculine scale, such a result does not guarantee pure and absolute femininity or masculinity; the instrument's items are only sampled from the theoretical constructs that represent masculinity and femininity. Item selection was based on theoretical background in the context of sensual and romantic relationships. In terms of validity, because the test employed was newly developed, theoretical and apparent validities were prioritized (Bernier \& Pietrulewicz, 1997; Cohen \& Swerdlik, 2009). Item sampling and content were reviewed by Lamontagne and 5 other trained judges, and were unanimously deemed to be appropriate. Some items were reverse-keyed in order to ensure coherent responses. For example, participants who scored high on the item "I tend to be the one to call my dates back" were expected to score low on the item "I usually wait to be called after going on a date with someone." Reverse-keyed items were designed to load negatively on the factor structure as well.

To avoid revealing the purpose of the test, the measure was presented to participants as a tool for identifying personality factors relevant to the selection of intimate partners. Deception was used to promote honesty on the part of the participants' and to avoid social desirability bias (i.e., sex-appropriate vs. sex-inappropriate). Whilst one could wonder if external influences such as societal norms projected by media could affect the responses collected, it is our belief that this wasn't the case for two reasons. Because objectality and subjectality are deemed to be innate psychological specificities, paragraph authors could be tempted to mask their true tendencies, if deviant, to comply with these said norms. This is why the purpose of the paragraph and test were not revealed. Moreover, because of the subjectal nature of some paragraphs received from male participants, and their above demonstrated tendency to comply to masculine norms, this further emphasized that participants answered honestly. Lastly, while media could have played a role to condition male participants to answer objectively while females subjectively, it is in fact theorized that media (especially musical) and art have long manifested the very innate concepts of objectality and subjectality (see Lamontagne's (2010) cover page for an example).

\section{Objectives and Hypotheses}

The primary objective of the present study was the re-evaluation of Lamontagne's (2010) initial hypothesis. Using the modified paragraph, a shift in scores toward the subjectal end of the continuum was expected in the female demographic (hypothesis 1). This hypothesis supports the symmetrical nature of masculinity and femininity proposed by the theory, and was the study's most important prediction. Where the male demographic was concerned, scores were expected to be consistent with previous findings, i.e., to gravitate toward the objectal end of the spectrum (hypothesis 2).

The secondary objective was the construction of the Questionnaire of Objectality and Subjectality (QOS) and the evaluation of its psychometric properties. The factor structure was expected to include two factors - one factor 
for masculinity and one for femininity (hypothesis 3 ). The subscales resulting from the bifactorial structure were expected to demonstrate reasonable to acceptable reliability (hypothesis 4). The scores obtained on the objectal and subjectal subscales were expected to correlate significantly with the masculine and feminine subscales of the BSRI, respectively. Correlations on the opposite scales were expected to be non-significant or significantly negative (hypothesis 5).

The third objective was to use the questionnaire and the modified paragraph to explore inter-sex differences. Men were expected to score significantly higher than were women on the QOS objectal items and verbs (hypothesis 6). Inversely, women's scores on subjectal items and verbs were expected to be significantly higher than were men's (hypothesis 7).

The final objective of the present study was to explore the intra-couple dynamic, that is, the complementarity or similarity of proportions of femininity and masculinity between partners. Past research has found evidence of both similarity and complementarity in couples in relationships (i.e., Acitelli, Kenny \& Weiner, 2001; Amodio \& Showers, 2005; Luo \& Klohnen, 2005; Markey \& Markey, 2007). Regardless of the variables being tested (personality factors, affectivity, religion, political attitudes), the goal of research of this nature is often to predict couple satisfaction. Since prior findings have been inconclusive across studies, evaluation of the intra-couple femininity/masculinity dynamic was exploratory in nature. However, it was anticipated that the intra-couple dynamic in couples would constitute one primarily objectal partner and one primarily subjectal partner (hypothesis 8). The objectal and subjectal partners are necessarily men and women, respectively; instances of heterosexual couples in which the man is primarily subjectal and the woman is primarily objectal may exist.

\section{Method}

\subsection{Participants}

A sample of 134 participants was recruited. The participants were between 18 and 32 years old $(M=20.93$, $S D=2.18$; 91 females). Eligibility criteria included: (1) a minimum age of 18 years; (2) sufficient knowledge of the English language; and, in the event that the partner was interested in participating, (3) a minimum duration of 6 months in the current relationship. The majority of participants $(n=123)$ identified as Canadian; other participants were Arab $(n=5)$, African-American $(n=2)$, or of another ethnic background $(n=4)$. Based on this sample, three subgroups were formed: men $(n=43)$, women $(n=91)$ and, within the overall sample of 134 participants, heterosexual couples ( $n=20 ; 20$ men and 20 women).

\subsection{Procedure}

Participants in an undergraduate psychology program were recruited. Professors advised students of the opportunity to receive a bonus point on their final grade for participating in the online study. Participants were provided with secure hyperlinks to the website (hosted on Survey Monkey) where they accessed the questionnaire package. If both partners in an intimate relationship participated, the partners completed the questionnaires independently. The study was approved by the university ethics committee and all participants provided informed consent prior to their participation.

\subsection{Measures}

A standard sociodemographic questionnaire was administered to participants in order to obtain information about sex, age, and ethnic background, among other variables.

\subsubsection{Modified "standardized" Paragraph}

Participants were asked to produce a paragraph describing a fictional ideal sensual encounter, incorporating 5 verbs conjugated actively or passively (i.e., in an objectal or subjectal fashion, respectively) (Note 4) amongst the other expressions they were free to include. In a blind procedure, six judges ( 3 men and 3 women, including Lamontagne) trained by Lamontagne scored the use of objectal (indicating the participant's desire to take, e.g., "I have dreamt of your body for so long"; "I want to kiss you") and subjectal (indicating the participant's desire to be taken, i.e., "I have dreamt of your hands on my body for so long"; "I want you to kiss me") verb forms in each paragraph (see Figure 1 for a detailed example of paragraph scoring). Each paragraph was neutralized prior to scoring in order to eliminate clues about the sex of its author (see Table 2). The sequences of paragraphs were randomized to eliminate fatigue and order bias on coding.

\subsubsection{Questionnaire of Objectality and Subjectality (QOS; Gabbay 2010).}

The questionnaire developed in the context of the present study was designed to determine participants' objectality and subjectality. Similarly to the paragraph used in Lamontagne's study, items were sampled in an effort to represent standardized typical romantic behaviour. The questionnaire was composed of 51 items; 
several neutral items ("I have good self-esteem") were included to legitimize the alleged objective of the study to participants. Respondents answered the questionnaire items using a 7-point self-report Likert scale; responses ranged from (1) Strongly Disagree, to (4) Neither agree nor disagree, to (7) Strongly Agree. Participants were also asked, in two separate text boxes, to describe their ideal partner for a relationship and their ideal partner for a sexual encounter, and to justify their responses. They were also asked to supply details about the beginnings of their current relationship, specifying which partner initiated contact and how. Participants who were single at the time of questionnaire completion were presented with the option of supplying details about an ex-partner. These tasks were designed to maintain the deception about the objective of the test, but the collected data could be used in a future study. The psychometric properties of the QOS are presented in the results section.

\subsubsection{Bem Sex Role Inventory}

The Bem Sex Role Inventory (BSRI; Bem, 1974) is a 60-item inventory designed to quantify androgyny on three 20-item subscales: (1) masculinity, (2) femininity, and (3) distracters. Respondents indicate their answers on a 7-point Likert scale ranging from (1) Strongly Disagree, to (4) Neither agree nor disagree, to (7) Strongly Agree. Possible scores on each 20-item subscale range from 20 to 140. Subscale scores are obtained by adding up the values obtained on each item of the subscale. The BSRI initially demonstrated a reliability of $\alpha=.86$ on the masculinity subscale and $\alpha=.82$ on the femininity subscale, and continues to demonstrate good psychometric properties (Oswald, 2004).

\section{Results}

\subsection{Preliminary Data and Inter-rater Reliability}

Prior to the principal analyses, the collected data was examined for potential outliers or missing data. Outliers were screened based on sex. Using z-scores with a 3.29 cut-off, no significant univaritate outliers were observed. Using the Mahalanobis distance, no bivariate outliers were identified. A final sample of 127 participants (the number of participants who completed the questionnaire package in its entirety) was retained. Of the 127 gender-neutral paragraphs, 117 paragraphs were appropriate for qualitative analyses; 10 participants did not follow the instructions correctly and integrated only non-conjugated verbs. The Kappa coefficients for inter-rater reliability (comparisons between pairs of judges) ranged from .83 to $.94(p<.01)$ when scoring subjectal (feminine) expressions used by women, from .89 to $.98(p<.01)$ when scoring subjectal expressions used by men, from .93 to $.99(p<.01)$ when scoring objectal (masculine) expressions used by men, and from .83 to .94 $(p<.01)$ when scoring objectal expressions used by women.

\subsection{Qualitative Descriptive Statistics}

In terms of frequencies, the proportion of men with greater than $50 \%$ objectality (masculinity) in their paragraphs was $68.75 \% ; 50 \%$ objectality was the cut-off point used to identify individuals as "primarily objectal". In contrast, the proportion of women with greater than $50 \%$ subjectality (femininity) in their paragraphs was $94.1 \%$. Further, the results of the analysis of the written paragraphs placed $80 \%$ of that $94.1 \%$ of women above $80 \% \mathrm{~S} / 20 \% \mathrm{O}$.

The cut-off was set at $50 \%$ for the purpose of parsimony, and because of its relation to the concept of "mainly objectal or subjectal." Though it is clear that men or women with $51 \%$ or $49 \%$ objectality or subjectality would likely be similar, this cut-off was retained for classification purposes. Ultimately, differences between men and women as groups were studied. The cut-off merely serves as reference when looking at descriptive statistics. Men's average proportion of objectality was $58.05 \%$, whereas women's average proportion of objectality was $12.39 \%$. Women's average proportion of subjectality was $87.61 \%$, whereas men averaged $41.95 \%$.

\subsection{Exploratory Factor Analysis of the QOS}

Due to the limited sample size $(N=127)$, exploratory factor analysis (EFA) with principal axis factoring was performed (Note 5). The EFA including only objectal and subjectal items extracted a 7-factor solution using Kaiser's stopping rule. Given the theoretical background of the newly created questionnaire, a bi-factorial solution was expected. Further, taking into account the steep drop of the Scree Plot around the $4^{\text {th }}$ or $5^{\text {th }}$ factor, and the abstract nature of the factors of subjectality and objectality, the initial solution seemed to reveal 4 main factors: the importance of aesthetics, the active pursuit of partners, the desire to be approached, and intimate security. Based on this analysis, the EFA was forced to 4 factors. No items loaded onto the $4^{\text {th }}$ factor, and the analysis was forced to three factors and re-performed. The inter-factor correlations were inferior to .30, indicating that an orthogonal rotation was more appropriate than a direct oblimin for this analysis (Grimm \& Yarnold, 2001). Consequently, the eigenvectors were transformed by varimax rotation to extract a simple factor 
structure. Typically, factor loadings superior to .30 are considered to be adequate (Grimm \& Yarnold, 2001). The three-factor solution was performed twice; items 51, 42, 50, 9, and 36 were removed.

The final extracted solution revealed factor loadings on the first factor (comprised of 12 items) ranging from - .51 to -.35 (subjectal items loading negatively on the objectal factor, as expected) and from .32 to .58 . Loadings on the second factor ( 11 items) ranged from .33 to .65. Loadings on the third factor (6 items) ranged from .38 to .68 . The extracted factor structure is presented in Table 3. The first factor (objectal) explained $15.19 \%$ of the variance, the second factor (subjectal) explained $12.15 \%$ of the variance, and the third factor (mixed) explained $8.79 \%$ of the variance. The three extracted factors explained a cumulative $36.06 \%$ of the total variance. The Kaiser-Meyer-Olkin $(\mathrm{KMO})$ coefficient was 0.68 (reasonable $=0.7$ ) and Bartlett's test of sphericity was significant $(p<.0001)$; the scores on both of these indices support the choice to use EFA (Norušis, 2008).

\subsection{QOS Reliability and Corrected Inter-item Correlations}

Internal consistency was also measured for the three extracted subscales. An alpha coefficient superior to .70 is generally considered to be acceptable (Grimm \& Yarnold, 2001). The alpha coefficient for the objectal subscale was .74; corrected inter-item correlations ranged from .20 to .50 , with an average of .37. The coefficient included subjectal (feminine) items that loaded negatively on this subscale and were re-coded into reverse-scored items. Items 3, 12, and 29 had the lowest correlations, but the results suggested that the suppression of these items would lower the subscale's alpha coefficient. Cronbach's alpha for the subjectal subscale was .76; corrected inter-item correlations ranged from .26 to .59 , with an average of .40. Items 5 and 8 had the lowest correlations, but the results indicated that preservation of these items would maximize alpha value. The alpha coefficient for the intimate security subscale was .75; corrected inter-item correlations ranged from .39 to .56 , with an average of .47. No items yielded unacceptable correlation coefficients. Considering the reliability analyses, no further items were deleted subsequent to the final EFA.

\subsection{QOS Convergent and Discriminant Validities}

Convergent validity is an index of the degree to which a test correlates with a simultaneously administered criterion measure (Cohen \& Swerdlik, 2009). In the present study, the convergent validity of the QOS was established by comparison to the BSRI. Because multiple correlations between variables were of interest, a Bonferroni correction was applied in order to reduce the risk of type I error. The acceptable family-wise alpha (.15) was therefore divided by the number of correlations, and only those significant at the .025 level would be considered significant. The results indicated that the objectal subscale (active pursuit of partners) was positively correlated with the BSRI masculinity subscale $(.297, p<.01)$. The subjectal subscale (desire to be approached) was positively correlated with the BSRI femininity subscale $(.268, p<.01)$. Finally, the intimate security subscale (mixed dimensions: both objectal and subjectal) was also correlated with the BSRI femininity subscale $(.465, p<.01)$.

Discriminant validity is an alternative index that indicates the degree to which a measure does not correlate or correlates negatively with a variable or test with which it is not intended to correlate (Cohen \& Swerdlik, 2009). The results indicated that the objectal subscale did not correlate with the subjectal subscale $(-.12$, ns.) and was negatively correlated with the BSRI feminine subscale $(-.22, p<.05, \mathrm{~ns})$. The subjectal subscale did not correlate with the BSRI masculine subscale $(.08$, ns.). Finally, the intimate security subscale did not correlate with the objectal subscale $(-.017, \mathrm{~ns}$.) nor did it correlate with the BSRI masculine subscale $(.03, \mathrm{~ns}$.).

\subsection{Quantitative Descriptive Statistics}

Based on the items included in the extracted factors of the final EFA, total subscale scores were calculated for each participant $(N=127)$ by adding up the scores for each item of the respective subscales. Possible scores ranged from 12 to 84 on the objectal subscale, from 11 to 77 on the subjectal subscale, and from 6 to 42 on the mixed subscale. On the objectal subscale (masculinity, factor 1), the average score for men in the overall sample was $50.13(S D=6.41)$; the average score for women was $38.89(S D=7.24)$. On the subjectal subscale (femininity, factor 2), women had a mean score of $59.45(S D=6.70)$, whereas men's mean score was $52.56(S D=7.59)$. Finally, on the intimate security subscale (mixed, factor 3), women had an average score of $42.78(S D=3.74)$, whereas men's average score was $40.42(S D=3.71)$.

\subsection{Significance of Inter-sex Differences}

\subsubsection{Quantitative Differences}

Means for scores were subsequently compared using independent sample $t$-tests (men and women, exclusively). On objectality, the test revealed a significant difference between the two groups' means, $t(121)=8.09, p<.000$. This is equivalent to a Cohen's $d$ of 1.64, a very large effect size (Tabachnick \& Fidell, 2007) On subjectality, 
the test also revealed a significant difference between men and women, $t(121)=4.88, p<.000$; equivalent to a Cohen's $d$ of .96, also a large effect size. Lastly, on the mixed subscale, no significant difference was observed, $t$ $(121)=1.77, p=.079$.

\subsubsection{Qualitative Differences}

The distributions of proportions of objectal and subjectal verb use in the participants' paragraphs were also compared using independent samples t-tests. The results revealed significant differences between men and women in average proportions of objectality, $t(115)=8.10, p<.0001$, and subjectality $t(115)=-8.10, p<.0001$. These values both correspond to Cohen's $d$ values of 1.46, a large effect size. The results of the comparisons reflected the anticipated proportions for each sex. That is, men's proportion of objectality was greater than was women's and, correspondingly, women's proportion of subjectality was greater than was men's.

\subsection{Intra-couple Analyses of Each Partner's Objectality and Subjectality}

Since the intra-couple analyses in the present study used dyadic data $(N=20$ couples; comprised of 40 individuals from the overall sample of 127 people), statistical analyses were conducted with the Hierarchical Linear Modeling (HLM) computer program. The dependent variable was the difference between the QOS femininity scores and the QOS masculinity scores of the two partners in each dyad. In HLM, a T-ratio test is used for final estimation of fixed effects; a Chi-square test is used for final estimation of variance composition (Raudenbush, Bryk, Cheong, Congdon, \& Du Toit, 2004). The results indicated that the average slope (difference between each partner) was significant $(t(19)=-2.54, p<.05)$, illustrating complementarities of proportions between partners, independent of sex (e.g., "masculine" men and "feminine" women or "feminine" men and "masculine" women). Further, the significant average slope was constant across the 20 couples in the sample $\left(\chi^{2}(19, N=20)=21.81, p>.05\right)$.

\section{Discussion}

The present study offers intriguing results regarding significant differences of men and women's experiences in their relationships, though theoretically, and hopefully by extension, regarding renewal of how sex role theories conceive what is masculine and feminine. First and foremost, the re-evaluation of Lamontagne's (2010) initial hypothesis seems to have been beneficial; the new proposal that women - as a group - are primarily subjectal, seems to be supported. Results collected from paragraphs with modified instructions (explicit choice between active and passive forms of conjugation) revealed a significant movement of the female group toward the subjectal end of the spectrum (as compared to the bimodal distributions observed in prior studies). Further, the use of new task instructions seem to have had an impact on the male participants as well; scores for male participants were less close to the extreme objectal end of the spectrum. However, as a group, men were still observed to be primarily objectal, and past studies based on these constructs have demonstrated that men's scores are usually distributed near the objectal end of the spectrum (see Lamontagne, 2010; Quintero, 2009).

To further evaluate gender differences, the extracted QOS factor structure was used to create subscales for scoring. The results demonstrated that the QOS was composed of three factors, a finding that appears to be congruent with the proposed theory, and partially confirms the second hypothesis. The dimensions of objectality and subjectality were anticipated, whereas the third mixed dimension was not. Items representing this factor were developed based on our expectations of men's and women's preferences for feeling secure (subjectal) versus providing security (objectal). For example, an objectal item on the mixed factor would be "I often like to hold my partner in my arms," whereas a subjectal one would state "I like being held or cuddled by my partner." Despite the obvious theoretical divergence, these items loaded on the same dimension: the mixed factor. As proposed above, this pairing could represent a statistical relationship rather than a real theoretical relationship; alternatively, this finding could suggest that some dimensions, such as intimate security (as reflected by item content on the mixed factor), are both feminine and masculine or neither feminine nor masculine. The latter proposition seems to push the boundaries of the theories presented here, and evokes the universal nature of the needs for security and love, as articulated by Maslow (Bouchard \& Gingras, 2007) and Bowlby (1969/1982). It may be interesting to compare the QOS to measures of adult and romantic attachment.

The calculated alpha coefficients for each subscale demonstrated acceptable reliability, particularly for a first-time administration of the test. However, the coefficients may have been affected by the small sample size, and may have been higher had a larger sample been used. Moreover, as anticipated, QOS subjectality and objectality subscale scores correlated with the BSRI feminine and masculine subscales, respectively, and non-significant or negative correlations were found for the inverse pairings. These results further reinforce the test's validity; that is, the QOS seems to adequately measure the concepts that it is designed to measure. Where the $3^{\text {rd }}$ factor (intimate security) is concerned, the results revealed a strong correlation with the BSRI feminine 
subscale. Though this finding could contradict the proposition that the desire for intimate security is universal, we must keep in mind that the BSRI characterizes the female role as one that is primarily oriented toward caregiving behaviour. Thus, the correlation between the QOS intimate security subscale and the BSRI feminine subscale is statistically coherent but theoretically debatable. Concerning validity, the unanimous agreement between Lamontagne and the 5 other evaluators on item content and sampling not only reinforces face validity, but also suggests that the theory presented here is sufficiently coherent to be replicated in a future study.

Results concerning proportions of subjectal and objectal verbs in participants' paragraphs and QOS subscale scores revealed significant differences between men and women. That is, men and women's scores diverged significantly and according to the theory presented here. Though these findings may seem predictable, verification was necessary in order to evaluate the utility of the newly created quantitative measure; the findings support the validity of the QOS. Intra-couple analyses demonstrated significant differences in proportions of objectality and subjectality between romantic partners. That is, in a couple, one partner was always found to be more masculine or feminine than was the other. The consistent differences between partners across the 20 couples are interesting in that they add a new area to be explored in research on conjugal complementarities versus similarities (cf. Dryer \& Horowitz, 1997). For example, future investigations could explore the reciprocity of intra-couple femininity and masculinity as it relates to various dimensions of relationship functioning. A longitudinal component would also be interesting; complementarities or similarities in proportions of feminine or masculine traits could potentially predict relationship success or failure.

\subsection{Future Research}

Although the findings of the current study are interesting, the sample size and composition may limit the potential for inference and generalization of the results. The size of the present sample is nevertheless adequate, and heterosexual men's tendencies toward objectality and heterosexual women's tendencies toward subjectality are difficult to dismiss. The composition of the study's sample constitutes a further limitation of the present study; being that a sample of primarily young Canadians is less than ideal and limits the generalizability of the results. However, it is worth mentioning that the theory was subject to cross-cultural validation with a Colombian sample in another study (see Quintero, 2009).

From an epistemological perspective, continued empirical testing with a larger sample would potentially allow refutation of certain parts of the theory. This type of research is preferable to the simple use of large-scale data collection to further support the current results, and would permit objective improvements to the theory, either by modifying the theoretical framework, or by incorporating certain co-variables as exceptional cases. One example would be the replication of the study with a sample of homosexual individuals. Sex roles in both gay men and lesbians have been reported to be comparable to those observed in heterosexuals (Schechory \& Ziv, 2007), suggesting that bimodal distributions would be observed in both men and women. Further, the cross-cultural validity of the theory could be explored with samples of individuals with diverse ethnic backgrounds; the QOS and the modified paragraph task have yet to be administered to culturally diverse samples.

\subsection{Conclusion}

The objective of the study presented here was to elaborate on pre-existing research results. A review of general findings revealed that the concepts of objectality and subjectality were present in many other studies, albeit without necessarily being qualified as such. The concepts of objectality and subjectality can be found in research about respective genders' motives in entertaining short-term sexual relationships (Jonason, Li \& Cason, 2009), adolescents' motives for pursuing relationships (Smiler, 2008), men's perceptions of women's bodies (Ward, Merriwether, \& Carruthers, 2006), and differences between men's and women's learning processes (Lamontagne, 2010), among others.

In the present study, the concepts of masculinity and femininity were elevated to a higher level of abstraction in an effort to separate traits from bio/psychological sex. Distinguishing traits from bio/psychological sex constitutes an important step in the evolution of research in the field of sex roles (Watzlawik, 2009). Based on this methodological strength, the theory of objectality and subjectality provides an approach that is applicable on very large scale.

Finally, the socialization of individuals in conformity with popular societal norms (reflected in the factor structures of the measures mentioned above) has been demonstrated to be detrimental to individual psychological well-being (Levant et al., 1992; Pleck, 1995). According to Levant et al. (2007), consequences of this phenomenon, known as Gender Role Strain (Pleck, 1995), include low self-esteem, difficulty in intimate relationships, high anxiety, alexithymia, and depression. Research has demonstrated negative psychological and 
social consequences of stereotypical ideologies (Schrock \& Schwalbe, 2009), leading to believe that the popularization of a more flexible conceptualization of sex roles could be beneficial for young men. The current rapid evolution of social norms seems to suggest that research could benefit from a renewed focus on primal differences between sexes. The arguments presented here hopefully represent a step toward responding to this mandate. Fellow researchers are encouraged to further pursue this effort.

\section{References}

Acitelli, L. K., Kenny, D. A., \& Weiner, D. (2001). The importance of similarity and understanding of partners' marital ideals to relationship satisfaction. Personal Relationships, 8, 167-185. http://dx.doi.org/10.1111/j.1475-6811.2001.tb00034.x

Amodio, D. M., \& Showers, C. J. (2005). "Similarity breeds liking" revisited: The moderating role of commitment. Journal of Social and Personal Relationships, 22, 817-836. http://dx.doi.org/10.1177/0265407505058701

Bem, S. (1974). The measurement of psychological androgyny. Journal of Consulting and Clinical Psychology, 45, 196-205. http://dx.doi.org/10.1037/h0036215

Bernier, J.-J., \& Pietrulewicz, B. (1997). La psychométrie: traité de mesure appliquée. Montréal: Gaëtan-Morin.

Bouchard, S., \& Gingras, M. (2007). Introduction aux théories de la personnalité. (3 ${ }^{\text {rd }}$ ed.). Montréal, QC: Gaëtan-Morin.

Bowlby, J. (1969/1982). Attachment and Loss: Vol. 1. Attachment, New York: Basic Books.

Brentano, F. (1874/1944). Psychologie du point de vue empirique, trad. M. de Gandillac. Paris: Aubier.

Cohen, R. J., \& Swerdlik, M. E. (2009). Psychological testing and assessment: An introduction to tests and measurement $\left(7^{\text {th }}\right.$ ed.). New York: McGraw-Hill.

Clatterbaugh K. (1996). Contemporary Perspectives on Masculinity: Men, Women and Politics in Modern Society. Boulder: Westview.

Connell. R. W. (1993). The big picture: Masculinities in recent world history. Theory and Society. 22, 597-62. [Online] Available: http://www.jstor.org/pss/657986

David, D., \& Brannon, R. (1976). The male sex role: Our culture's blueprint for manhood, and what it's done for us lately. In D. David \& R Brannon (Eds.), The fortynine percent majority: The male sex role (pp. 1-48). Reading: Addison-Wesley.

Dryer, D. C., \& Horowitz, L. M. (1997). When Do Opposites Attract? Interpersonal Complementarity Versus Similarity. Journal of Personality and Social Psychology, 17, 592-603. http://dx.doi.org/10.1037/0022-3514.72.3.592

Grimm, L. G., \& Yarnold, P. R. (2001). Reading and understanding multivariate statistics. Washington, DC: American Psychological Association.

Flood, M., Gardiner, J.K., Pease, B., \& Pringle, K. (2007). International Encyclopedia of Men and Masculinities. London: Routledge.

Jonason, P. K., Li, N. P., \& Cason, M. J. (2009). The Booty Call: A Compromise Between Men's and Women's Ideal Mating Strategies. Journal of Sex Research, 46, 460-470. http://dx.doi.org/10.1080/00224490902775827

Lamontagne, C. (2010). Qui a peur d'une pédagogie différentielle des sexes? Collected Essays on Learning and Teaching, 3, 15-20. [Online] Available: http://www.phaenex.uwindsor.ca/ojs/leddy/index.php/CELT/article/view/3233

Levant, R. F., \& Fischer, J. (1998). The Male Role Norms Inventory. In C. M. Davis, W. H. Yarber, R. Bauserman, G. Schreer, \& S. L. Davis (Eds.), Sexuality-related measures: A compendium (2nd. ed., pp. 469-472). Newbury Park: Sage Publications.

Levant, R. F., Hirsch, L., Celentano, E., Cozza, T., Hill, S., MacEachern, M., Marty, N., \& Schnedeker, J. (1992). The male role: An investigation of contemporary norms. Journal of Mental Health Counselling, 14, 325-337. [Online] Available: http://www.eric.ed.gov/ERICWebPortal/search/detailmini.jsp?_nfpb=true\&_\&ERICExtSearch_SearchValue_0= EJ449693\&ERICExtSearch_SearchType_0=no\&accno=EJ449693

Levant, R. F., Richmond, K., Cook, S., Tanner House, A., \& Aupont, M. (2007) The Femininity Ideology Scale: Factor Structure, Reliability, Convergent and Discriminant Validity, and Social Contextual Variation. Sex Roles, 57, 373-383. http://dx.doi.org/10.1007/s11199-007-9258-5 
Levant, R. F., Smalley, K. B., Aupont, M., Tanner House, A., Richmond, K., \& Noronha, D. (2007). Initial Validation of the Male Role Norms Inventory - Revised (MRNI-R). The Journal of Men's Studies, 15, 83-100. http://dx.doi.org/10.3149/jms.1501.83

Lisak, D. (2000). Editorial. Psychology of Men and Masculinity, 1, 3. http://dx.doi.org/10.1037/1524-9220.1.1.3

Luo, S., \& Klohnen, E. C. (2005). Assortative mating and marital quality in newlyweds: A couple-centered

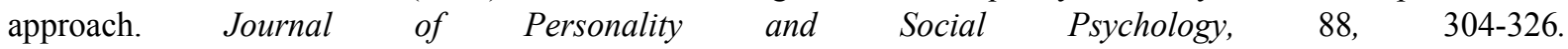
http://dx.doi.org/10.1037/0022-3514.88.2.304

MacInnes, J. (1998). The End of Masculinity: The Confusion of Sexual Genesis and Sexual Difference in Modern Society. Philadelphia: Open University Press.

Markey, P. M., \& Markey, C. N. (2007). Romantic ideals, romantic obtainment, and relationship experiences: The complementarity of interpersonal traits among romantic partners. Journal of Social and Personal Relationships, 24, 517-533. http://dx.doi.org/10.1177/0265407507079241

Noar, S., \& Morokoff, P. (2002). The relationship between masculinity ideology, condom attitudes, and condom use stage of change: A structural equation modeling approach. Journal of Men's Health, 1, 43-58. http://dx.doi.org/10.3149/jmh.0101.43

Norušis, M. J. (2008). SPSS 16.0 Guide to Data Analysis. Upper Saddle River: Prentice Hall.

Oswald, A. (2004). An examination of the current usefulness of the Bem sex-role inventory. Psychological Reports, 94, 1331-1336. http://dx.doi.org/10.2466/PR0.94.3.1331

Pascoe, C. J. (2007). Dude, You're a Fag: Masculinity and Sexuality in High School. Berkeley: University of California Press.

Pleck, J. H. (1995). The gender role strain paradigm: An update. In HY. Brid (Ed.), The making of masculinities: The new men's studies (pp. 21-38). Boston: Allen \& Unwin.

Porkert, M. (1973). Theoretical Foundations of Chinese Medicine: Systems of Correspondence. Cambridge: MIT Press.

Quintero, N. (2009). Contributions empiriques et théoriques à une nouvelle théorie de la psychologie de la féminité et de la masculinité : validité interculturelle et rapport avec les concepts d'activité et de passivité. Unpublished honors thesis, University of Ottawa, Ottawa, Ontario, Canada.

Raudenbush, S., Bryk, A., Cheong, Y. F., Congdon, R., \& Du Toit, M. (2004). HLM 6: Hierarchial Linear and Nonlinear Modeling. Lincolnwood: Scientific Software International, Inc.

Schrock, D., \& Schwalbe, M. (2009). Men, Masculinity and Manhood Acts. Annual Review of Sociology, 35, 277-295. http://dx.doi.org/10.1146/annurev-soc-070308-115933

Shechory, M., \& Ziv, R. (2007). Relationships between Gender Role Attitudes, Role Division, and Perception of Equity among Heterosexual, Gay and Lesbian Couples. Sex Roles, 56, 629-638. http://dx.doi.org/10.1001/s11199-007-9207-3

Smiler, A. P. (2004). Thirty Years After the Discovery of Gender: Psychological Concepts and Measures of Masculinity. Sex Roles, 50, 15-28. http://dx.doi.org/10.1023/B:SERS.0000011069.02279.4c

Smiler, A. P. (2008). "I wanted to get to know her better": Adolescent boys' dating motives, masculinity ideology, and sexual behaviour. Journal of Adolescence, 31, 17-32. http://dx.doi.org/10.1016/j.adolescence.2007.03.006

Smith, E . R., Byrne, D., \& Fielding, P . J. (1995). Interpersonal attraction as a function of extreme gender role adherence. Personal Relationships, 2, 161-172. http://dx.doi.org/10.1111/j.1475-6811.1995.tb00083.x

Tabachnick, B. G., \& Fidell, L.S. (2007). Using Multivariate Statistics (5th Edition). Needham Heights, MA: Allyn \& Bacon.

Taywaditep, K. J. (2001). Marginalization Among the Marginalized: Gay Men's Anti Effeminacy Attitudes. Journal of Homosexuality, 43, 1-29. http://dx.doi.org/10.1300/J082v42n01_01

Ward, L. M., Merriwether, A., \& Caruthers, A. (2006). Breasts Are for Men: Media, Masculinity Ideologies, and Men's Beliefs About Women's Bodies. Sex Roles, 55, 703-714. http://dx.doi.org/10.1007/s11199-006-9125-9

Watzlawik, M. (2009). When a Man Thinks He Has Female Traits. Constructing Femininity and Masculinity: Methodological Potentials and Limitations. Integrative Psychological and Behavioral Science, 43, 126-137. http://dx.doi.org/10.1007/s12124-008-9085-4 


\section{Notes}

Note 1. Though it is clear that all humans feel the desire to both love and be loved (Bouchard \& Gingras, 2007), this statement is based on the fundamental difference between masculinity and femininity: if forced to choose between loving and being loved, masculine individuals would choose to love, whereas feminine individuals would choose to be loved. This phenomenon is illustrated in typical courtship behaviours, and the findings that women or feminine individuals generally prefer to receive attention, to be proposed marriage, etc.

Note 2. Evidently, not all heterosexual men are homophobic. However, a significant core of males must endorse this ideology in order for this factor to be empirically validated in a psychometric inventory. Homophobia is mentioned here as being a trait rather than a belief based on the MRNI-R's authors' description of it being included in the 7 traits comprising traditional masculinity ideology.

Note 3. Applicable to the widest range of women and men, respectively, though not exclusively.

Note 4. This was the most typical way to code but does not imply that men are exclusively active and women exclusively passive. An example of active subjectality would be to make active in efforts to wearing makeup or dressing up and looking good in the hopes of attracting potential subjects as mates (versus efforts to pursue potential objects, as would active objectality).

Note 5. The primary EFA was performed using only items that were designed to be objectal or subjectal, excluding all distracters. Since it is generally essential to include all test items when performing EFA, distracters were included in a separate analysis. As expected, the results demonstrated that most distracters items did not load on the objectal or subjectal dimensions, nor did they load on a separate dimension. In cases in which distracters loaded on objectal or subjectal dimensions, factor loadings were logical. For example, items such as "Generally, I have good self-esteem" loaded onto the objectal subscale. It is logical that good self-esteem has an impact on active pursuit of potential partners. Distracters were nonetheless excluded from the main EFA because their content was not linked to the theoretical concepts, and their inclusion would have affected calculations of total scores for each dimension.

Table 1. Comparison of initial and modified qualitative tool instructions

\begin{tabular}{|c|c|}
\hline Lamontagne's initial qualitative tool instructions & Modified qualitative tool instructions in the present study \\
\hline $\begin{array}{l}\text { In the blue text box below, compose a few sentences } \\
\text { (roughly } 10 \text { lines, in whichever format you prefer } \\
\text { [poem, prose, song lyrics...]) that express your fantasies } \\
\text { (sentiments, images, desires, all words that come to } \\
\text { mind) when it comes to a first ideal sensual encounter } \\
\text { with the perfect partner. The idea here is to let flow this } \\
\text { fantasy with all the imagination your mind is capable of. } \\
\text { Try not to over think: write impulsively, in the moment, } \\
\text { following your spontaneous instincts. Click on } \\
\text { "Submit" to send the text. A brief example, from a point } \\
\text { of view amongst many: "... whispering in their ear: I } \\
\text { have long waited your caress, to passionately kiss you, } \\
\text { to drown in your gaze, hopelessly intertwined..." Try to } \\
\text { incorporate as many words of the following list: "to } \\
\text { gaze ", "to hold (in one's arms) / to embrace", "to touch } \\
\text { / caress", "to kiss", "to desire", "to dream", "lips, } \\
\text { hands, body ..." etc. Dare to write down all words that } \\
\text { come to mind. }\end{array}$ & $\begin{array}{l}\text { Please write a fictional paragraph, according to your personal } \\
\text { preferences, describing an ideal sensual encounter or fantasy } \\
\text { between you and a partner. Though you are not limited to } \\
\text { your choice of words, you must incorporate the following } \\
\text { verbs in this paragraph: To love/To be loved (someone/by } \\
\text { someone); To kiss/To be kissed; To touch/To be touched; To } \\
\text { hold/To be held; To caress/To be caressed. } \\
\text { As we are interested in your personal opinion and } \\
\text { preferences, please refrain from using the "we" form as best } \\
\text { possible. }\end{array}$ \\
\hline
\end{tabular}


Table 2. Comparison of initial and gender neutral paragraphs

\begin{tabular}{|l|l|}
\hline \multicolumn{1}{|c|}{ Example of an actual initial paragraph } & \multicolumn{1}{c|}{ Example of the gender neutral paragraph } \\
\hline $\begin{array}{l}\text { I first met her and I knew she would like to be held, } \\
\text { caressed and touched. I went up to her and asked her } \\
\text { what her name was, she replied: "It will take more than } \\
\text { that to find out." I immediately knew she would be the } \\
\text { best I ever had, given the opportunity. She was looking } \\
\begin{array}{l}\text { for a good time, to be loved and to love, be kissed, } \\
\text { caressed and fondled. I just knew I had to have her. }\end{array}\end{array}$ & $\begin{array}{l}\text { I first met him/her and I knew he/she would like to be } \\
\text { held, caressed and touched. I went up to him/her and } \\
\text { asked him/her what his/her name was, he/she replied: } \\
\text { "It will take more than that to find out." I immediately } \\
\text { knew he/she would be the best I ever had, given the } \\
\text { opportunity. He/She was looking for a good time, to be } \\
\text { loved and to love, be kissed, caressed and fondled. I just } \\
\text { knew I had to have him/her. }\end{array}$ \\
\hline
\end{tabular}

Table 3. QOS factor structure after varimax orthogonal rotation

\begin{tabular}{|c|c|c|c|}
\hline Items & $\begin{array}{l}\text { Factor } 1 \\
\text { Objectal }\end{array}$ & $\begin{array}{l}\text { Factor } 2 \\
\text { Subjectal }\end{array}$ & $\begin{array}{l}\text { Factor } 3 \\
\text { Mixed }\end{array}$ \\
\hline \multicolumn{4}{|l|}{ Objectal } \\
\hline $\begin{array}{l}\text { When single, I enjoy the chase in pursuing a } \\
\text { potential partner more than being chased. }\end{array}$ & .579 & - & - \\
\hline I tend to be the one to call my dates back. & .560 & - & - \\
\hline I like taking people out on dates. & .546 & - & - \\
\hline $\begin{array}{l}\text { I prefer to make the first move, when single or in } \\
\text { my relationships. }\end{array}$ & .540 & - & - \\
\hline $\begin{array}{l}\text { I usually wait to be called after going on a date with } \\
\text { someone. (S)* }\end{array}$ & -.512 & - & - \\
\hline $\begin{array}{l}\text { Hypothetically, I'd rather pick up than be picked } \\
\text { up. }\end{array}$ & .498 & - & - \\
\hline $\begin{array}{l}\text { When single, I'd prefer to let potential partners } \\
\text { come to me and initiate conversation rather than } \\
\text { approach them.(S)* }\end{array}$ & -.462 & - & - \\
\hline $\begin{array}{l}\text { As a single person in social contexts (bars, clubs, } \\
\text { parties), I would prefer to approach people who } \\
\text { interest me rather than be approached. }\end{array}$ & .370 & - & - \\
\hline $\begin{array}{l}\text { When about to have a first kiss with someone, you } \\
\text { are more likely to look them in the eye and wait for } \\
\text { them to kiss you rather than leaning in. }(\mathrm{S})^{*}\end{array}$ & -.361 & - & - \\
\hline $\begin{array}{l}\text { When single, I often feel like I am the one pursuing } \\
\text { intimate partners more than being pursued. }\end{array}$ & .355 & - & - \\
\hline $\begin{array}{l}\text { Sexually submissive partners are more attractive } \\
\text { than dominant ones. }\end{array}$ & .321 & - & - \\
\hline $\begin{array}{l}\text { If I had to choose a preference, I would prefer to } \\
\text { love someone than be loved by someone. }\end{array}$ & .321 & - & - \\
\hline
\end{tabular}


Continued (Table 3)

\begin{tabular}{|c|c|c|c|}
\hline Subjectal & & & \\
\hline $\begin{array}{l}\text { When single and getting ready to out, if putting } \\
\text { effort into looking good for yourself, it would also } \\
\text { be in hopes of attracting the attention of potential } \\
\text { partners. }\end{array}$ & - & .646 & - \\
\hline $\begin{array}{l}\text { I would agree that looks are an important part of } \\
\text { what draws me to people. }\end{array}$ & - & .533 & - \\
\hline $\begin{array}{l}\text { If I were in an elevator with mirrored walls, I would } \\
\text { tend to look at myself on the way up or down. }\end{array}$ & - & .520 & - \\
\hline $\begin{array}{l}\text { I enjoy spending time on my aesthetic appearance } \\
\text { (hair, clothes, etc.). }\end{array}$ & - & .516 & - \\
\hline $\begin{array}{l}\text { When single, I sometimes feel aggressive in the } \\
\text { way that I seek out partners by drawing them to me. }\end{array}$ & - & .499 & - \\
\hline $\begin{array}{l}\text { When single and getting ready to go out, if I were to } \\
\text { put any effort in my aesthetic appearance, it would } \\
\text { be geared towards looking good in order to avoid } \\
\text { rejection from the people I would approach. }\end{array}$ & - & .466 & - \\
\hline $\begin{array}{l}\text { As a single person in social contexts, I would prefer } \\
\text { to receive attention rather than give it. }\end{array}$ & - & .456 & - \\
\hline When dating at first, I play hard-to-get. & - & .394 & - \\
\hline $\begin{array}{l}\text { Sexually dominant partners are more attractive } \\
\text { than submissive ones. }\end{array}$ & - & .381 & - \\
\hline $\begin{array}{l}\text { I prefer to have people approach me with a } \\
\text { compliment rather than approaching people and } \\
\text { complimenting them. } \\
\text { Mixed }\end{array}$ & - & .376 & - \\
\hline I often like to hold my partner in my arms $(\mathrm{O})$. & - & - & .680 \\
\hline I like being held or cuddled by my partner (S). & - & - & .634 \\
\hline I like partners that make me feel safe $(\mathrm{S})$ & - & - & .539 \\
\hline I feel good when people show interest in me (S). & - & - & .488 \\
\hline $\begin{array}{l}\text { When in a relationship, I feel protective of my } \\
\text { significant other }(\mathrm{O}) \text {. }\end{array}$ & - & - & .482 \\
\hline I like buying my partners presents $(\mathrm{O})$ & - & - & .382 \\
\hline
\end{tabular}

Note. Items marked with an asterisk were recoded into reverse-keyed items during final score calculations for subscales. Items in the extracted factor structure are not in exact order of administration. Researchers interested in using this measure may contact ngabb095@uottawa.ca for the correct order of administration, and may only use the questionnaire with written permission. 


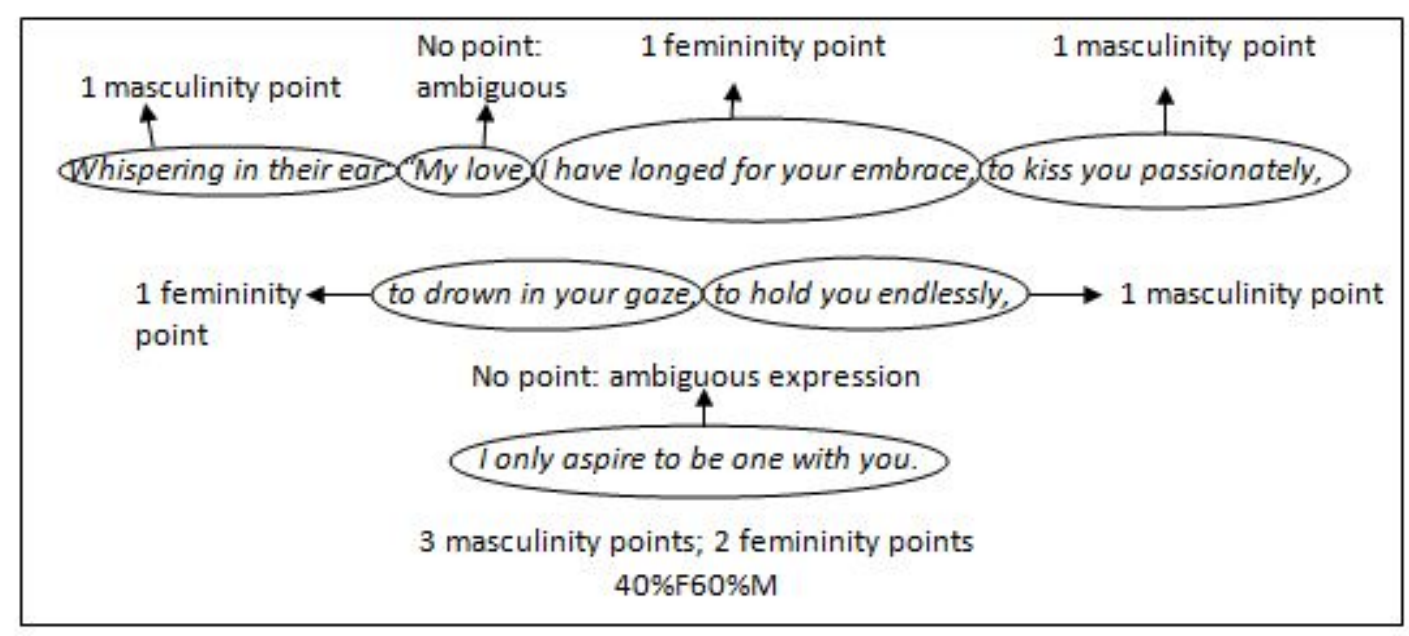

Figure 1. Simplified example of paragraph coding for objectal and subjectal use of verbs 